\title{
A Critical Study on the Implementation of the Total Quality Management in Directorate General of Project and Engineering Affairs in Ministry of Health, Oman
}

\author{
Khalid Saif Salim Al-Nadabia \\ Dr. Maria Teresa Matriano
}

MIDDLE EAST COLLEGE

\begin{abstract}
Total quality management or TQM has become one of the most important mechanisms for organizations that offers unique products or services to satisfy customers and achieve organizational goals. It is the core of management in the 21 st century to provide better services and strive for customer and supplier satisfaction as well as maintaining a good relationship with the owners. The problem that this research focuses on is that the organization does not use a quality system or policy at work and therefore management faces a major problem on cost and effort in training staff. This has led to a lack of trust of the client as well as stakeholders in the services provided by the institution. The study primarily focused on understanding the application of TQM in Directorate General of Project and Engineering Affairs (DGPEA) office in Ministry of Health, as well as the challenges and issues in the performance of the work. The study has proposed a framework for improving TQM in DGPEA and in increasing the efficiency and quality of service. The researcher used descriptive methodology to collect qualitative and quantitative data through survey questionnaire and interviews. Judgmental purposive sampling technique was used with a more representative sample. It was concluded in the study that organization should focus on cooperation in creating a healthy work environment and for continuous improvement of all operations as well as reducing redundancy and unnecessary functions. The recommendations addressed the topmanagement concerns, and operational TQM issues aiming at strengthening the strategies adopted in the application of TQM in accordance with international standards.
\end{abstract}

\section{Introduction}

Currently, Total Quality Management (TQM) is becoming one of the most significant mechanisms of the work of any organization that provides unique products or services to satisfy customers and achieve organizational objectives. Therefore, quality management in organizations is very important, as it has been the core of management in the 21st century. Moreover, the quality management system is very important for many institutions, whether government or private because they enhanced performance and achieve the desired goals of the organization (Murray and Frenk, 2000). The Total Quality Management (TQM) also enhances performance management throughout the planning, implementation, analysis, evaluation and re-planning of the processes (Jaafari, 2001). The research aims to explore the effect of Total Quality Management (TQM) policies on organizational performance at the Directorate General of Projects and Engineering Affairs DGPEA in the Ministry of Health MOH. According to Arditi.D \& Hurat.H (2000), TQM is described as an approach that fundamentally intended to create and bring high quality products and services that fulfill all clients' expectations and attain their satisfaction at a top level.

\section{The Research Problem Statement}


The organization relies on an old work routine that does not have any policy or specifications to rely on in the implementation of its procedures of each job and activity. This is a significant problem and burden on management and the organization on cost and effort in training staff. Moreover, this has led to distrust of the client as well as stakeholders in the services provided by the organization.

\section{The Aim and Objectives of the Study}

The aim of the study is to understand the application of TQM in DGPEA, so that it can be used for policy making. The researcher will focus on these objectives to know the challenges and problems in the performance of the work and the best practices as well. It aims to develop as well a framework for improving TQM in DGPEA ultimately to increase the efficiency and quality of service. To enrich this concept, the efficiency and effectiveness of applying TQM in DGPEA will be considered, in relation to measuring stakeholders' overall satisfaction.

\section{Specific Objectives}

1. To evaluate the impact of TQM in DGPEA overall performance.

2. To evaluate the role of IT in TQM and it's overall impact in improving DGPEA performance.

3. To assess the TQM best practices in DGPEA.

4. To develop a framework for improving TQM practices in DGPEA.

\section{Research Questions}

1. What are the impact of Total Quality Management (TQM) in Directorate General of Projects and Engineering (DGPEA)?

2. What is/are the role(s) of information technology in Total Quality Management (TQM) and its overall impact in improving Directorate General of Projects and Engineering (DGPEA) performance?

3. What are the ways to assess the Total Quality Management (TQM) best practices in Directorate General of Projects and Engineering (DGPEA)?

4. What new framework can be recommended to DGPEA to improve more the implementation of TQM?

\section{Expected Outcomes}

A TQM report that will bring clear understanding of the standards of TQM in DGPEA and will meet the overall objective of understanding the application of TQM in DGPEA in the Ministry of Health in Oman.

TQM standards are international standards that are widely used in many countries of the world. Therefore, they are new to the General DGPEA. First, the decision makers in the Directorate require a deep understanding of the TQM policy as well as awareness of the employees on the concept of TQM implementation and the overall goal of applying it in DGPEA. This policy will assist the senior management in making the appropriate decision as well as to define the employees with the controls and procedures according to the system of total quality management in order to achieve quality and efficiency at work.

1. A report on the critical investigation about the role of IT in Total Quality Management (TQM) and its impact in improving the performance of DGPEA. The outcome is expected to show that IT has a large influence on TQMs. This is very important as IT can lead to the increase of its success. TQM are being affected by technological changes. The growth of technology is rapid, and organizations should try to adapt fast. Today's technology is one of the most important elements in improving the efficiency of the work and the quality of the materials provided to the customers. 
A report on best Total Quality Management (TQM) practices in DGPEA through standardized methodology on vigorous and smooth workflow in (DGPEA). This will be achieved by day to day monitoring of DGPEA practices and activities. In addition, teamwork with the organization staff is performed to ensure that the implementation of TQM in different projects and routine operations are in place with minimal efforts, time and resources that are in accordance with TQM standards.

A framework that will improve the TQM practices in DGPEA will be developed. TQM practices would not be effective without an implementation framework. The framework will provide the users with guidelines on how to apply TQM effectively and efficiently and who are the stakeholders that will be involved in the implementation process. The guidelines shall be mandatory to be followed by the organization staff from bottom to top management level. This framework will provide maximum customer satisfaction and continuous improvement for DGPEA. The DGPEA shall understand the extent of achieving a desired outcome and its purpose accordingly. Overall, the framework shall ensure that the work done in DGPEA is of highest quality.

\section{Significance of the Study}

This research will have the theoretical importance of covering the quality standards and aspects of Total Quality Management, and its role in supporting the quality performance management in the DGPEA, as well as other organizations in different fields in Ministry of Health, which would increase the efficiency and quality of services that will be provided by the organization in the least time, effort and cost. It will also increase the knowledge in Total Quality Management area (TQM) for the DGPEA and to researcher as well. The study is highly connected to researcher's new job and customer satisfaction for the services or products provided by the DGPEA. Furthermore, the Ministry of Health has a reputation for providing distinguished health services to the community and must be preserved. So will describe the significance to the several stakeholders as follows:

\section{The Significance of the Study to Future Academic Researcher}

The significance of the study for future academic researcher is to conduct another relevant research on TQM to increase the researchers' knowledge on the methods and procedures required for the application of TQM in the organization.

\section{The Significance of the Study to Ministry of Health}

The results of this research will provide the Ministry with the reduce cost, effort and time in the research and analysis of the challenges and solutions in the process of applying TQM. The specialists in DGPEA in the Ministry of Health can reach the appropriate decision to solve the obstacles and improve performance in the workplace, the role of IT to improve the performance, the use of best practices and framework for TQM practices, through the recommendations of this research.

\section{The Significance of the Study to Other Organizations}

There are some transactions between the Ministry of Health and other organizations. This study will include the procedures followed in these transactions, which can be transferred to the electronic system by a technological link in which the procedures are completed in lesser time with less effort and cost. It will also help decision making by providing all documents electronically according to TQM standards in the application of technology on the services provided by the Ministry of Health.

\section{The Significance of the Study to Clients}


This study will include the implementation of Total Quality Management, which facilitates and reduces the processes undertaken in the ministry in the implementation of services, as well as the use of technology that will accommodate the different types of customers. So, the goal of the success of TQM is customer satisfaction as well as facilitating a high quality service in conducting transactions between the Ministry of Health and their clients.

\section{Scope of the Study}

The scope of the research will be on Total Quality Management in the DGPEA in the Ministry of Health. The research will cover the role of information technology in the field of overall quality management in the organization and its impact on improving overall performance. The research will focus on the best practices of TQM and its development to improve the work of the organization. The study tends to answer various research questions that will achieve the objectives of the research project. The scope of research tends to focus on the application of IT for all services and procedures provided by DGPEA to its customers and it will cover the importance of research to internal and external stakeholders, and most importantly, the benefits from the application of TQM to the Ministry of Health.

\section{Limitations of the Study}

Researcher faced some cultural restrictions during the period of preparation. This was during the holy month of Ramadan where working hours were limited. This has great impact to research deadline. The summer is a vacation season and most of the staff during this period was on a holiday. In addition, there were some complexities in the collection of academic resources, particularly the most up-to-date academic resource. As for the questionnaire, there was some concern in the way the respondents responded to the questionnaire and finally to the interview sessions with five directors at the DGPEA at the Ministry of Health. They didn't have enough time for the interview or to answer the research questions. As regard to TQM relevant issues and concerns, the details of periodic review and evaluation of the TQM processes and practices will not be covered by this study, instead, it will be part of the recommended future research,

\section{The Definition of Operational Terminologies}

Total Quality Management (TQM): A term used to describe management approaches in improving the quality of services provided or in improving products. It is also an approach that promotes customer satisfaction. In other words, TQM is a term to provide best quality service or product in a correct manner (ASQ, 2019). TQM was established in 1954 in Japan in the industrial sector and then was used in all sectors such as education, commerce, services and the electronic business sector. It is also defined as doing business properly from the first time and over and over again. This concept leads to the provision of time to correct the work and services that will be provided to customer such as warranty repairs (Toolshero, 2019).

\section{Literature Review}

\section{Introduction}

This chapter will present some theoretical thoughts and related literature centered on similar studies that has been done in the field of Total Quality Management (TQM). Moreover, implementation of TQM in healthcare project planning organizations, will be covered. Impact of TQM on organizational performance and operational challenges facing TQM are listed. Finally, it will be concluded by highlighting best practices for TQM. 


\section{Journal of Student Research}

Fourth Middle East College Student Research Conference, Muscat, Sultanate of Oman

The effect of TQM policies on organizational performance at the DGPEA, according to (Arditi.D \& Hurat.H, 2000), is described as an approach that fundamentally intended to create and bring high quality products and services to fulfill all clients' expectations and attain their satisfaction at a top level. The organization provides standard operating procedures for its services as a functional guidance to standardize the format and the procedures for managing activities related to department. Thus, the use of TQM improves customer satisfaction and achieves the best results for the services provided by the organization.

\section{Benefits and Importance of TQM}

TQM is established in the form of an established set of principles, and formalities that ensure the output that conforms to the required quality standards. Without guidelines, specifications, and targets, the quality standards cannot be set. Therefore, it is imperative that organizations are willing to implement TQM, design, and establish a certain framework that has the required quality standards to be met. From this, it can be inferred that TQM is beneficial in an organization to provide much needed guidance in improving the organization goals and objectives. It helps the organization to focus more on improving their operations and output. This can improve the organization image and general outlook. The better the public image, the more customers they will get and hence, more profits.

By providing quality guidance framework, TQM enables the organization to have better detection and prevention of deviation that can derail the companies from meeting their objectives (Charantimath, 2011). This is because TQM details all the required quality standards to be met, and thus provides a back-check for any deviations. This is because it details all the technical specifications, work processes, workflow diagrams, documents, and the required level of output. This forms the backbone of the organization. Moreover, if it is designed well enough, it can provide excellent and essential guidance for the company to meet its objectives.

TQM is essential because it emphasizes on the management to put efforts to enhance customers experience and satisfaction (Charantimath, 2011). If the projects can satisfy the customers, they will be more useful, and worth the time and the finances committed to them. This is because, project are usually designed to be used by people, and thus they should be designed with customer satisfaction in mind to provide the best user experience for them.

If not, users will not be attracted to the projects, and they will be a waste of resources since they have not achieved their purpose. Therefore, TQM provides requirement in line with the customer's desires and needs, and the planning and design of the projects should be in line with these requirements. The main objective of TQM is to ensure that the degree of customer satisfaction to be obtained acts as a measurement of the level of quality to be achieved by the project. Therefore, if all the focus is on the satisfaction of the customers, after completion, most of them will be attracted by the project, increasing its utility.

TQM is not only critical in building customer satisfaction, but also helps in building good relationships with suppliers. The quality of the project is usually affected by the goods and services provided by the suppliers. If they provide low-quality raw materials, the project will be of low quality and might even collapse and not serve its purpose. According to Charantimath (2011), a good quality policy that is agreed with the suppliers encourages crucial links cooperation and introduces the multiplier effect. This ensures good relations between the suppliers and the company so that they can supply quality products and services for the project.

According to Charantimath (2011), one of the critical components of TQM is members commitment, involvement, and participation in the organization processes. This works jointly with managerial support. As suggested by Agus (2011), members participation from a broad decentralization, improve the company's flexibility, nimbleness to change, and increases the capacity to change. This 
provides key factors for the development of creative and qualified workers. The workers are very important in the development and implementation of the projects. Moreover, as much as TQM requires the participation of all workers and other stakeholders, their commitment to the project is what guarantees the success of the project. Therefore, it does not matter how good the project is in the planning stage; if the implementation personnel is not committed to the project, it is most likely to fail.

\section{Implementation of TQM in Healthcare Project Planning Organizations}

In cases of stiff competition, companies can find ways of cutting cost, even if it reduces the quality of the products they sell. However, this can be very dangerous and detrimental to clients in the healthcare sector. These are sick people that need urgent medical care and any service that is below the acceptable standards, might lead to loss of life. Thus, the need for TQM in the healthcare sector. However, competition is not always disadvantageous; according to Talib et al. (2011), it can lead to healthcare institutions trying to develop better and more efficient ways of providing their services. However, Adindu (2010) argues that the provision of quality services in the healthcare sector depends on the availability of resources and qualified staff. Moreover, in order for the health facilities to be able to provide quality services sustainably, they must be able to afford the required resources in the long run. Therefore there is a need for TQM to strike a balance between quality services and the cost incurred, for sustainable service delivery. This is especially so, for private hospitals, that do not benefit from government funding (Adindu, 2010). Thus they would need to run their operation sustainably.

Another problem that faces healthcare institutions and requires the urgent interventions of TQM is the rising cost of healthcare provision. This has been a burden for both the government and private hospitals. Since there is a need to maintain quality healthcare, the rising cost can present a challenge to service delivery. This creates a need to have better ways of managing the required quality standards, and the cost incurred and a balance sought. Without quality management, people can aspire for high-quality standards that they cannot sustain, and after a short while, they shut down this is not beneficial to the customers. Only sustainable quality levels should be attained, with adequate and optimal cost requirements incurred.

The high cost of healthcare can create severe tax burdens for the government. Examples of countries that have suffered this fate are the U.S, the UK, Canada, and Taiwan (Sanchez-Serrano, 2011). This can create a debt crisis and a fall in businesses providing healthcare services. Therefore, Talib et al. (2011) suggest that governments and businesses need to reexamine their operation strategies so that they can decrease the operational costs and increasing the quality of services. This can be achieved through the use of technology and other innovative ways of reducing cost and maintain high-quality standards. This can be done by having an effective and efficient TQM strategy (Dale, 2011). According to Balasubramanian (2016), TQM in the healthcare industry is a comprehensive strategy of a health unit to change the way they do things, and to train medical personnel on the best practices for improving quality methods. This should be done, so that they can meet their patient's requirements, and be able to reduce costs. This definition is supported by James \& Savitz, (2011) argues that TQM is meant to streamline the operations of a health organization to improve its service delivery while reducing the cost of healthcare delivery. In most developed nations who aim to have high standards of healthcare service, the cost of healthcare is skyrocketing (Joseph, 2013, p. 19). This is despite health insurance coverage. Therefore, TQM provides an effective strategy to reduce the cost of healthcare services, and maintaining high standards.

With TQM, the hospitals can transform and modify their traditional quality improvement systems to more customer-centric approaches. This is the general concept behind TQM, finding the best ways to provide the best user experience possible; all business operations should be focused on 


\section{Journal of Student Research}

Fourth Middle East College Student Research Conference, Muscat, Sultanate of Oman

customers' utility, even in as much as they do for profits. It is a case of getting the flowers, and the butterfly come to you-in this case, the flowers are quality services and products for customers, while the butterflies are the customers. It can also be thought of as a farmer planting flowers that attract bees; then the bees produce honey. In this case, the flowers are quality products and services, the bees are customers, while honey is the profits the business will get. So TQM is an indirect approach of improving the business process and getting more customers, which in turn translates to higher profits.

Even though the use of TQM practices has been widely accepted in most hospitals, their implementation is still wanting. There is a lack of commitment in the implementation of TQM in the healthcare sector. This is the case even though most studies have found out that the use of TQM in hospitals improves the healthcare delivery processes and service, and reduces the costs. Most studies have been done to evaluate the factors that affect the implementation of TQM (Yih, 2016). However, the research of TQM practices in the healthcare sector is limited (Talib et al., 2011).

According to Mosadeghrad (2014), the successful implementation of TQM is that hospitals require quality control, a broad approach for quality progress monitoring, and the development of an incorporated performance measurement system. On the other hand, Charantimath, (2011) argues that the strategy and the nature of network relationship in a hospital setting between the healthcare providers and patients are significantly related to the actual performance of TQM adoption. Another study by Talib et al. (2011) showed the application of a market share model for achieving the competitive advantage of TQM in the healthcare sector. They concluded that TQM improves the organizational effectiveness and market share of healthcare institutions. The problem is that most studies do not focus on supervision and control of TQM in the healthcare facilities, as they have done in the manufacturing sector.

The main issue that limits these studies as discussed by Talib et al. (2011) is the differences between these two industries, and the need for quality and the definition differs. In the manufacturing industry, the focus is mostly on the quality of products that are sold to consumers, while in the healthcare sector, the focus is on the service that is delivered to the patients. Kelkar S. A, (2010) studied the innovative approaches and continuous improvement of TQM, and reported that it saved time, helped to streamline processes and reduced costs. This is very beneficial in the healthcare sector, especially with the ballooning cost healthcare in most countries. They also reiterated that public hospitals and large hospitals most likely apply TQM in their operations. As for small hospitals, they mostly prefer to use continuous improvement as a tool for quality management-it is more convenient and economical for them. However, even is as much as large hospitals apply TQM in their operations, they do not do it as efficiently as they should, this is due to the scale of their operations that acts a barrier ( Mosadeghrad, 2014). This is reiterated by Kaynak \& Rogers, (2013) who concluded that TQM in large hospitals would require a lot of commitment from the management who most of the time ignore it. That is the main problem that TQM faces in large organisation-there are so many recesses to focus on TQM, and thus most them just ignored it.

The application of TQM in hospitals is touted by many researchers to have the potential to mitigate the financial crisis in the healthcare sector. It can also reduce the milliard of problems that engulf the healthcare sector, and thus streamline healthcare delivery. This is essential for any nation, and a healthy nation will encourage people to be active in economic production. The many problems affecting the healthcare sector might drive most hospital to adopt TQM strategies. Therefore, as stated by Talib et al. (2011), TQM can become a very useful tool for managers and decision makers in the hospital to improve their operations.

\section{Impact of TQM on Organizational Performance}

According to Talib et al. (2011), one of the keys of TQM is the ability to encourage the participation 


\section{Journal of Student Research}

Fourth Middle East College Student Research Conference, Muscat, Sultanate of Oman

of all the employees, management and other stakeholders into teamwork that working in unity towards a common goal. This helps to get rid of sectionalism and enables the organization to work as an entire unit and cooperate to improve the quality of their products and services. In this way, TQM can improve organizational performance by enhancing the unity of all the stakeholders in the organization. A unified organization works better to improve quality than a disorganized one. This is because they can collaborate and consult one another so that they can work together to achieve their goals. This enhances the flow of processes in the organization.

Talib et al. (2011) argue that TQM assists in process management. In an organization, process management is crucial for the achievement of high-quality standards and management of quality. In a healthcare facility, it emphasizes on conformance to patient requirements through the provision of error-free services. This should be done in the most efficient way possible so that the customer (who is the patient) will get the best experience possible from the services they get. Therefore, TQM streamlines organizational performance to give customers the best user experience possible.

The TQM has several components; one of them is the customer-related processes. For customerrelated processes, the business-customer interface is divided into two components that is output to customers and input from customers. Most of the research has been on customer complaining behavior that would hurt the repurchase intentions and brand loyalty. This can significantly affect business performance and reputation-something needs to be done before the business fails. Su, Tsai, \& Hsu (2010) suggest that customer relations can be improved by effective and meaningful customer interaction. This can be achieved via direct customer contact with the company's staff. This personal interaction with the staff creates an atmosphere of trust and will dispel any misunderstandings. This can be achieved through direct face to face contact, deliveries, telephone calls, or sales visits. Without proper customer contact, the organization will not be able to understand the perception of customers regarding their organization. Moreover, this denies them useful data they can use to improve the quality of their services. Also, customers vary in their preferences, and thus cannot be treated the same. Total quality management encourages customer segmentation so that their different needs can be catered differently. This can be achieved by market research to understand consumer behavior and provide products and services that are designed for specific market segments. Most organizations have different ways of getting customer feedback. However, some of the most effective methods are, setting up a website, where customers can give their feedback and suggestion on the types of products and service they would like from the company. The main objective of TQM is to provide a means of understanding customers' needs so that all the processes are designed to meet these needs only. Any process that is not focused on customer satisfaction is not a priority and can be eliminated to reduce costs.

The overall customer satisfaction has an effect on their loyalties over a wide section of products and services from the company. TQM streamlines the processes and customizes products and services to meet specific customer preferences. In TQM, quality is defined by the customer and is what the customer says it is. If a company develops products that they think are of high quality, but customers think otherwise, it will be redundant and no one will buy it. However, if they provide a product or service that customers like, they will have many sales that will translate to high profits and business growth. Thus all companies' processes should be designed and implemented by customers' preferences. This means that all companies should have a way of getting customers feedback and preferences so that they know what they want. This impacts positively on the organization performance.

\section{Operational Challenges Facing TQM}

Even in as much as TQM is beneficial to companies, a study conducted by McKinsey and Co showed that TQM programs that are in operation for more than two years are considered by about twothirds of the employees to be failures or redundant (Kaynak \& Rogers, 2013). The failure of TQM programs can largely be attributed to none compliance, where the people who are supposed to 


\section{Journal of Student Research}

Fourth Middle East College Student Research Conference, Muscat, Sultanate of Oman

implement the programs are not complying with the recommendations, and failed due to lack of a shared vision. This created divergent views that scatter the focus needed for proper implementation of TQM, and thus lead to its failure.

A climate of compatibility is necessary for TQM to be effective. This means that when a TQM strategy is designed, it should be compatible with the company's cultures and mode of operations. This will make it easy for it to be adopted in the organization. However, if it is not compatible with the organization's culture, processes and goals and visions, it stands very little chance of being successful. According to Leon (2008, p. 538), effective TQM cannot be highly compatible with the company's culture. This is because, if it is similar to the company's culture, then how it can bring change. On the other hand, most employees who are accustomed to the company's cultures will rarely support programs that bring abrupt change to the organization (Leon, 2008). This might be the reason why most TQM programs do not succeed beyond two years.

Another problem that leads to TQM failure is organizational commitment. If the company is not committed to implementing the TQMS strategy, then it will fail. This is usually done by the management. However, according to Oakland (2012, p. 276), most organizations hardly put enough effort to implement TQMs. This is because they do not see it as a top priority. They put much effort into designing and planning the TQMs but little time and effort implementing them. Oakland, (2012, p. 276) argues that in order for TQMS to be effective, the implementations stage is very crucial and requires close monitoring and evaluation.

Another operation challenge facing TQMs is lack of training for the employees to learn the new requirements. If the workers are not trained on the contents of the TQM, they might find it hard to implement it. However, according to (Noe, Hollenbeck, Gerhart, \& Wright, 2017), most organizations do not train their employees on the new requirements of TQM. This presents a technical challenge, because if the employees do not understand what they are implementing, how they can implement it effectively. Training is a critical factor in the implementation of TQM (Noe et al., 2017). TQM focuses all the efforts of all the members so that it can improve the operational efficiency of all the organization processes, increase the value to the clients while relying on a clear vision of the company's goals.

\section{TQM Best Practices}

Total quality management is based on quality management principles related to ethical behavior, social responsibility, values, and the need for customers satisfaction in order to increase the success of the company (Tarí, 2011). Social responsibility is one of the important pillars of TQM. For instance, it is included in the management excellence models, such as the European Foundation for Quality Management (EFQM) model or the Malcolm Baldrige National Quality Award (MBNQA) (Tarí, 2011). However, according to Tari (2011), little research has been conducted on social responsibility and quality management at the same time while some scholars have already identified that quality management practices can lead to the development of environmental management (Bansal, Phatak, \& Sharma, 2015, p. 101). This is because most of the organizational processes will be managed so that they can reduce not only wastages but also do it in a very environmentally friendly approach. According to Weidinger, Fischler, \& Schmidpeter, (2013) organizations that apply TQM in their workflow are environmentally conscious-they know that the environment has a significant effect on the quality of products and services that are produced by the organization This is because it affects their organizations sustainability issues (Tung, Baird, \& Schoch, 2014).Therefore, they ensure that environmental management is part of their TQM strategy.

The TQM practices that are mostly mentioned in most research papers on the topic are people management, leadership, customer focus, information and analysis, supplier management, process management, project planning and product design (Bernardo, et al., 2015). For instance, in order to 


\section{Journal of Student Research}

Fourth Middle East College Student Research Conference, Muscat, Sultanate of Oman

increase the quality of services provided by an organization, they need to manage their employees so that they can be able to handle customers; and give them the best service possible. Therefore, it is crucial to continuously manage the employees, and assign duties and functions to them according to their skills and expertise; and to continuously improve their skills and knowledge base through continuous training and education.

An effective TQM, which is a holistic management philosophy, requires good leadership; and mostly for leaders who are effective and efficient; who perform their duties through integrity, and the skills, knowledge, and expertise required of them. Good leadership ensures that all the organization's resources are efficiently utilized and reduce wastes-and make optimum use of the resources to maximize production and improve customer exercise. Good leadership is concomitant with a customer focus (Mendenhall et al., 2013). All the organization's goals, products, and services should be designed with customers' interest in mind. Since the reason why the organization was started was to serve the customers, why not focus all the attention on providing the best user experience ever (Tarí, 2011). Quality of products and services should be measured in terms of user experience, who dictate the market forces (Boone \& Kurtz, 2012). According Needham \& Dransfield (2001) the aim of any organization should be to meet the needs, tastes and preferences of its consumers; that is why any organisation that uses TQM must consider the customers preferences first before anything else.

TQM best practices demand that all the organization's processes should be appropriately managed to ensure efficient use of resources. Process management will also ensure that everything is done in time and reduce delays. This will translate to an excellent customer experience where they get their products and service on time (Tarí, 2011). TQM does not meant for the origination only, but also to stakeholders, the society, and customers. It is meant to increase the overall value of the company by improving the quality of the products and service they produce. This will, in the end, give a better user appeal and satisfaction rating and a good perception in the society. Therefore an organization's social responsibility deals with the legal, economic, philanthropic, and ethical expectations from society and the government (Dahlsrud, 2008). A company with a bad user rating and social perception does not last for long.

According to Anoye (2015), to ensure that TQM is successful, best practices are a must so that they can merge well with the organizational processes. It should be viewed as a routine function of the organization, and not just a task to be completed. This is because TQM is a process not an event or a task. One of the TQM best practices is quality management planning which is an integral part of the company's objectives. According to (Talib et al., 2011) the second most important best practice for quality management is process monitoring. All the company's processes need to be monitored to ensure that there are minimal disruptions that might affects quality and lead to losses.

Furthermore, the systematic approach to quality management is considered to be a best practice for TQM. These means that things should be done in order. All the quality management processes are interrelated, and thus they should be identified and analyzed individually-because they are all crucial for the betterment of the organization. When a problem is detected (Talib et al., 2011) argues that the best TQM practice is to analyze it not just identifying it; while (Nallusamy, 2016; Talib et al., 2011) notes that the main issue is not for firms to find ways of fixing problems when they arise, but to detect them early enough; and have mitigation measures to prevent their occurrence.

\section{TQM Framework}

According to Adeoti (2011), TQM framework can be described as a collaborative way of working. It relies on both the skilled labor of employees and the management to improve the productivity and quality of their service using the team. In order for TQM to be successful, its framework requires three main components. These are the use of teams, participative management, and continuous 


\section{Journal of Student Research}

Fourth Middle East College Student Research Conference, Muscat, Sultanate of Oman

improvement. In this framework, the attitude of both the employees and the management is very crucial for the success of the company. For instance, if the employees see themselves as crucial components for the provision of quality products and services, they will be motivated to give their best performance. Oakland (2012) identified a series of compositions that makes up the TQM framework. These are organizational factors, process factors, economic factors, customer focus, teamwork, interpersonal factors, facilities factors, employees' participation, empowerment, and environmental factors. Adeoti (2008) identified the critical factors required in the TQM framework in the healthcare sector and organized them, as shown in figure 1.

Figure 1. TQM Framework in the Healthcare Sector (Adeoti, 2011).

The study by Adeoti (2011) was able to identify three additional factors that are important to the TQM framework. These factors are information factors, drug factors, and technology factors. From his study, he found out that the economic factors were redundant in the healthcare sector. This is because most public hospitals are not affected by financial status since they are funded by the government. However, employee contribution was one of the most dominant factors of TQM that affects healthcare delivery quality. Therefore he concluded that if the government gives adequate funding, and the employees give their best (in terms of skills and commitment), then the quality of healthcare can be significantly enhanced.

TQM is a framework designed to improve organizational processes and efficiency (Bou-Llusar, Escrig-Tena, Roca-Puig, \& Beltrán-Martín, 2009). It caters for cost reduction while maintaining good quality. TQM aims to strike a balance between internal processes and quality management in trying to manage the processes as much as possible, without compromising on the quality of production. It is a case of finding the best internal fit with the most exceptional opportunities. According to Kyriazoglou (2012), the framework for TQM can only be managed when the organization can monitor both the internal and external environment, and the customers' needs continuously. This is meant to collect vital information that can be used by decision makers so that they can make sound decisions based on credible and reliable data. This is also meant to establish and maintain a strong horizontal and vertical communication, cooperation, and collaboration of all the individuals in the organization (Kyriazoglou, 2012). When there is efficient communication within the organization it works as a unit and thus is able to achieve its goals.

According to Friedli, Basu, Bellm, \& Werani (2013), efficient communication enhances collaboration within the organisation, which resulted to better quality management practices. The main purpose of a TQM framework is to create a delighted customer base, by streamlining processes and empowering employers that lead to higher returns at low cost (Doyle, 2009). The problem is that it is a pure paradigm and philosophy of change (Green, 2012). It does not have physical structures and legal requirements, but a series of recommendations meant to improve customer relations and the company's revenue. Because it does not have a solid framework, it is not easy to implement without willingness from management and employees. Thus most organizations find it difficult to implement TQM requirements (Green, 2012). This leads to a gap between what needs to be done and what is done. The problem is that maintaining a high level of quality in an organization requires inputs from all the stakeholders (Talib et al., 2011). Moreover, the fact that sometimes it collides with the personal interests of most of the stakeholders, some of them do not support it. TQM is not a destination but a journey towards improvement that needs constant monitoring. The problem is that constant monitoring might require extra resources, and most organization do not see it as a priority and thus will not invest in TQM (Green, 2012). The issue of prioritizing on TQM is crucial if the recommendations are to be effective. People as individuals or groups are the main component of a TQM framework: it cannot function without them. Therefore, when they support it, it works, and when they do not, it fails. The TQM framework is anchored on the organization-how the employees and the processes are arranged crucial for the provision of quality services and products to the customers (Palmer, Akin, \& Dunford, 2009). The employees and the process form the framework of the organization. If they are managed properly, the framework is robust, but if they are not managed properly the framework is weak; and quality is compromised. 
The TQM framework relies on a constant purpose in order to achieve products and services to get a competitive advantage by developing a new philosophical ideology (Dale, 2011). This ideology is based on continuous improvement of the system of production to improve productivity and quality, and in the process, reduce cost, to get a competitive advantage. It also encourages the organization to invest in training employees to embrace the new paradigm that will, in the end, encompass the whole organization (Tidd \& Bessant, 2018). If all the employees understand the requirements and the benefits of the new strategy (TQM strategy), they will most likely do their best to support it. The framework encourages organizations to reduce wastages, and find a balance between efficient operations, low cost of production, and quality of products and services (Dale, 2011). There should also be a monitoring system designed to check on the progress of TQM so that it is managed efficiently and effectively (Oakland, 2012). Quality stands for conforming to specific standards and customers' expectations.

\section{Synthesis of the Chapter}

From the studies reviewed, it was clear that TQM is very crucial for quality improvement in most organizations, especially the healthcare and manufacturing sectors. It is a holistic method and philosophy focused on maintenance and continuous improvement of all the processes and functions of an organization. It encourages collaboration between employees and management of the organization in order to improve the efficiency of the processes and improve the quality of the services and products while reducing costs of operations. For the most part, this is done through the reduction of redundancies, wastes, and unnecessary functions. All employees and management work together to improve customers' experience. The main aim of quality management is customer satisfaction. The organization must do its level best to improve their customer experience. This is because with a higher level for customer experience, comes a higher level of quality management, that translates to better company performance. Most of the research reviewed focused on the TQM in the manufacturing sector, while only a few focused on the health sector. The health sector is a susceptible industry; quality management is paramount. Furthermore, most of the research papers focused on the reasons why TQM strategies fail or are not popularly implemented in most organization. They do not look at the processes and the framework of TQM.

\section{Summary of the Chapter}

This chapter covered previous studies that focused on healthcare in quality management and improved performance to achieve customer satisfaction. Most of these studies encouraged community work and collaboration in creating a healthy working environment as well as the nonrepetition of work among departments in the organization to save time and effort. After collecting the information of TQM from secondary resources, the next chapter will cover an explanation of the research methodology that will be used by the researcher to gather important data and information through the primary sources. The researcher will explain the sampling methods and the size of the respondent population in DGPEA. This research will fill a gap of queries in TQM and to further the objectives of this research study.

\section{Research Methodology}

This chapter will cover the discussions on research methodology which the researcher used to collect data using both the qualitative and quantitative research methods approach Details of research methodology will be presented as well; the research plan, research's population, sampling and sample size, sampling method, data collection processes and the data analysis tools. It will provide as well the ethical, legal, and social aspects of this research.

\section{Research Design}


Descriptive research is intended to collect quantitative and qualitative data by answering questions about participants through surveys, and interviews conducted with employees and specialists of the organization, or through observation adopted by the researcher in this study, highlighting the issues facing management in total quality management through data collection (Jamie Hale, 2019).

\section{Qualitative and Quantitative Research}

The quantitative and qualitative data will be conducted by collecting it from employees through survey questionnaire and interview. Quantitative and qualitative data are concentrated in TQM and in the efficiency of performance, role of technology, best practices that are handled in the finalization of work and finally in the writing of the framework in achieving the objectives of the organization. The Figure 2 Shows the research stages used in this project.

\section{Primary Data Collection "Questionnaire and Interview"}

\section{Questionnaire Design}

The questionnaire is a survey conducted by the researcher to obtain quantitative information from the staff of the organization covered by the research. The questionnaire contains closed-ended questions related to the objectives of the study. The questionnaire will cover four objectives with four parts as follows:
A. Overall Performance of the DGPEA's TQM.
B. Role of IT in TQM and its Overall Impact.
C. Total Quality Management (TQM) Best Practices.
D. Framework for TQM Practices.

The questionnaire will contain two types of questions, the open and closed-ended questions. While closed questions contain specific answers, the open questionnaires contain how, why, what-and allows the respondent to express themselves. Questionnaire has two open-ended questions to collect the most valuable inputs from the respondents on TQM.

\section{Interview}

This is the second part of data collection. The researcher has met with the directors of departments in the DGPEA and asked some open-ended questions about TQM. During the interview, the researcher obtained information from four participants who are the decision makers of the company. The researcher prepared the following open questions, which are concentrated in the scope of TQM, which will be presented in the interview with the respondents from the DGPEA in Appendix A2.

The respondents to interviews are the experts/directors of the following departments in the organization:

DETA Department of Engineering Technical Affairs

DMT Department of Medical Technologies

DoM Department of Maintenance 


\section{Journal of Student Research}

DoP Department of Project

HR Human Resource

The interviews focused on five open-ended questions and meeting schedule was set with these experts. The researcher was based on the selection of managers in the organization with at least 5 years of experience.

\section{Observation}

Monitoring means observing the performance of staff in the organization and how the work is proceeding using the overall quality standards. This observation helps to know the level of services, practices and activities provided by DGPEA. It was observed that teamwork is carried out with the organization's staff to ensure the implementation of TQM in various projects and routine operations in place with minimum efforts, time and resources that comply with the overall quality standards. In this research study, the researcher got the approval of the research work from Directorate's office by securing the letter of no objection (Appendix A3).

\section{Secondary Data Collection}

The collected data in this research in the field of TQM gave foundation and background for the study. The researcher relies on the methods most commonly used in academic studies to complete the research. Secondary data was collected by category like relevant websites; books (Total Quality Management and Six SIGMA for (Escobar, 2015), and journals. Journals such as EBSCO, Science direct, JSTOR, SAGE, and other credible journal sites were considered for secondary data collection.

\section{Population and Sampling Size of the Study}

The target population of the study are employees in the DGPEA with at least one year experience. These are the respondents to survey questionnaire. The questionnaire focused on the best practices and the quality management aspects of the organization which are very much understood by those employees who have stayed at least one year in the organization, hence, those newly hired and with experience lesser than one year were not considered for the study. From the organization's record, it was revealed that only 105 employees have at least 1 year experience. The judgmental purposive sampling technique was considered for this study. This is a non-probability technique where a well representative sample was selected to come up with a more accurate results. Sampling size was computed using below formula. (ThemeHorse, 2019) N0 = (Z2 p q / e2).

So $\mathrm{p}=0.5$. Suppose researcher focus wants $95 \%$ confidence, and at least $5 \%$ more or less of precision. A $95 \%$ confidence level gives us $\mathrm{Z}$ values of 1.96, per the normal tables, ((1.96)2 (0.5) $(0.5)) /(0.05) 2=385$. Here $\mathrm{n} 0$ is Cochran's sample size recommendation, $\mathrm{N}$ is the population size, and $\mathrm{n}$ is the new, adjusted sample size. So with 105 employees in the target population, we would calculate sample size as $385 /(1+(384 / 105))=83$

Figure 3. Sample size of population

Total number of respondents $=(($ Total No of Employees in Department $) /$ Total Staff of the Organization) $*$ Total target Sample). Example, DMT $=(19 / 105) * 83=15$

Table 1. Total Number of Respondents in DGPEA.

The population of the study is 105 and this is based on the total employees of the organization with 
at least one year of experience. This includes the department managers, department heads, engineers, consultants, and employees who understood very well the issues, challenges and best practices of TQM.

\subsection{The Validity and the Reliability of the Research Instruments}

The questionnaire of the study are being tested for validity and reliability. A pre-pilot test was conducted on five (5) carefully selected experts (mostly officials and specialists in TQM). With the Cronbach Alpha statistical results of (0.953), items in the questionnaire are verified and approved, as the deletion of any of them will still retain high reliability.

\section{Data Analysis}

The analysis of the data in this research is done using the nominal and sequential method using graphs and detailed tables of data obtained by questionnaire and interview using SPSS Statistical software and MS EXCEL, where tables and graphs were prepared for each question in this research for better understanding of results. (GUN, 2019)

\section{Ethical, Social, and Legal Issues}

\section{Ethical Issues}

In this research study, the researcher selected experts in their fields to participate in answering the research questions. This study will maintain the confidentiality of information collected. The researcher has completed as well the Research Ethics form as attached in the appendix A6 part of the paper for this purpose. Furthermore, to avoid any societal ethical problem either at the present time or in the future, the researcher got the approval of the DGPEA to conduct interviews and distribute the questionnaire to the employees to obtain the information and data that the researcher aims to obtain to complete the study. Research methods focused on obtaining general data in the area of TQM and avoid any questions about the participant's personal data such as name, email, address, and phone number. (Khalil , 2010)

\section{Social Issues}

The social problems faced by employees at work are dissatisfaction at the workplace or the manager's treatment with employees such as bias and irritability, lack of adequate training of staff or absence of periodic staff awareness, incentives or compensation or lack of material and nonmaterial compensation Housing, food or long working hours. (GUN, 2019) These social problems lead to low employee productivity, behavioral change in dealing with clients, reduce of development or improvement in work performance. (GoodTherapy, 2019) So, this research will look at all these social problems of staff and find out why they occur in order to make appropriate recommendations to avoid these future challenges.

\section{Legal Issues}

This part is covering the issues facing the researcher while doing any research. This research will also deal with legal issues, for example, the researcher knows the system and the laws followed in the case of disclosing data, the researcher is exposed to the legal question. This means that all information and data will be considered confidential and is for this research only. The legal issues of the researcher are an important element in the research study. The researcher must be familiar with legal issues in the Sultanate of Oman. For this reason, the researcher has signed the ethical form according to the applicable law, whether it is ethical towards the individuals involved in responding to the research methods or the organization's direction. At any rate, the researcher is 
obliged not to disclose any information to others, if this happens he will present himself to the judiciary. (Khalil, 2010).

\section{Summary of the Chapter}

This chapter covered the research methodology which included the use of questionnaire and interview in data collection. This methodology will clarify the qualitative and quantitative data analysis as illustrated in next chapter. The researcher used descriptive statistics as well as some correlation analysis. The results of the interviews were analyzed as well. The fourth chapter will discuss the presentation of the results and the analysis in addition to the results that will be published by the researcher. It will present the research analysis, and findings of the data sampled over quantitative and qualitative study (interviews and questionnaire) that were defined in the previous parts of the study.

\section{Data Analysis}

\section{Introduction to Data Analysis}

This chapter covers two parts, first is the presentation of findings of questionnaire analysis (using SPSS and MS Excel) and second part is analysis of interview results. This will reveal the presentation of above findings by analyzing both the quantitative and qualitative results of this study. These results will be critically analyzed and evaluated.

\section{The Research Analysis}

\section{Presentation Background of Research Analysis}

The questionnaire contained 25 closed questions and two open questions focused on all the research objectives of the DGPEA application. The objectives focused on the overall performance, the role of technology, best practices and the final framework in TQM. The questionnaire prepared for this study was distributed electronically to all employees in the DGPEA. 83 of the questionnaire was filled by DGPEA staff, according to study sampling size. As explained above, the research methodology is to collect qualitative data through interviews with five DGPEA's managers.

\section{Analyzing Results of the Questionnaire}

The introduction to the questionnaire contains some questions about general statements of respondents such as gender, nationality, academic qualifications, age and years of work. This illustrates the scientific and practical levels of the staff working in the organization. The tables show numbers, frequencies and percentage statistics result of questionnaire. While the figures show the statistical mean reported by the respondents for each question.

Table 2. Respondent's Status

\section{Correlation}

Table 3. Correlation between Nationality and Performance

\section{Correlation between Nationality and Performance}

The table 3 showed a weak or negative relationship between Nationality and Performance according to the Pearson correlation value (-.097). This relationship is inverse due to the high performance indicators in the organization. Thus, there are other influences that led to the 
weakening of this relationship.

\section{Correlations between Variables}

\section{Correlation between Performance and Academic Qualification}

According to the Pearson correlation value, the result in table 4 showed (.059) positive relationship between employee's performance and academic qualification. Conclusively, there is a direct relationship between the two variables that means when organization has high number of employees who has postgraduate studies, this will have a direct relationship to increase the employee's performance in DGPEA.

\section{Correlation between Performance and Role of IT}

The table 4 showed a strong direct relationship between the two variables Performance and Role of IT. According to the Pearson correlation value (.329), the greater the role of technology use in the organization, then performance of staff will increase. This indicates the importance of the role of technology to improve performance.

\section{Correlation between Performance and Best Practices}

The table 4 showed a good relationship between performance and best practices and according to the Pearson correlation value (.273), when using best practices of TQM in the organization, this will positively affect performance. This is clear that best practices are very useful in organizing time and work for an employee.

\section{Correlation between Role of IT and Best Practices}

The Pearson correlation value results in table 4 showed (.479) strong relationship between Role of IT and Best Practices of TQM. Conclusively, there is a direct relationship between these variables that means when organization using both two variables will lead to provide good quality services for customer.

\section{Questionnaire Content}

\section{Part A. Overall Performance of the DGPEA's TQM}

"Overall Performance of the DGPEA's TQM" is part ' $A$ ' and it includes 5 questions. This is the first part of questionnaire about the efficient employees' performance in DGPEA, as well as the benefits from the application of TQM despite the high cost and time spent in applying it in the DGPEA. This part contains 5 inquiries and each question include 5 options for answer: strongly agree, agree, neutral, disagree and strongly disagree. This research included the Likert scale as the rest of the research at the level of academic studies in the distribution of surveys and analysis of the results obtained by the researcher from the questionnaire. Each question has 5 answers and the respondent was asked to choose the most appropriate one from the list. As shown in Table (2) that each answer has been assigned a value $(1-5)$ and thus the researcher can put a value to conduct the survey and interpret the results. In this mode, the academic researcher can schedule the results and find the most frequent number. (Contributor, 2019).

\section{Part B. Roles of IT in TQM and its Overall Impact}

This section seeks to explore the role of IT in the improvement of work and employee's performance in DGPEA, and this section contains 5 question with 5 options for answer: strongly agree, agree, neutral, disagree and strongly disagree. The questions and results were as follows. 


\section{Part C. TQM Best Practices}

This area of research highlights the best practices adopted by the organization in TQM. This will define clear processes, policy and framework for quality performance. This part of the questionnaire contains 5 questions and each question has 5 specific answers that (strongly agree, agree, neutral, disagree and strongly disagree) for the respondent to choose the appropriate answer. All these questions focused on best practices.

\section{Part D. Framework for TQM Practices}

This is the final part of the closed-ended questions in questionnaire that focused on Framework for TQM Practices.

\section{Part E. Valuable Inputs}

This is the last part of the questionnaire, which includes two open-ended questions. These two questions focused on ' best practices for TQM and how to support and improve the overall quality management in the organization.

\section{E.Q1. 1. Based on your expertise, what would you recommend as a best practices for TQM in your organization?}

Below are the summary of responses to this open-ended questions on best practices:

\section{Strategic:}

1. Develop a five-year annual, immediate and monthly action plan with follow-up for comprehensive implementation.

2. Introducing the comprehensive quality system for each institution.

3. Provide clear guidelines, policies, flowcharts or procedures that will certainly help to increase the quality of work.

4. A general survey was conducted in Oman on the services provided by the Ministry of Health, then inventory these views and work to improve them.

\section{Operational}

1. Using advanced techniques to help achieve total quality.

2. Create a model to test and run the system to determine if the same applies to organization.

3. Proper coordination of all departments including end user and relevant committees if necessary. Without this, it would not be effective for the organization.

4. Must perform well according to the following criteria: leadership, strategy, workforce and operations the adoption or use of SWOT analysis for each project will enable the organization to reduce or avoid risks for future projects.

5. Keep a record of previous projects to learn from the mistakes made and prevent them from happening in future projects

6. Using technology, applying the ISO standards according to the exact work regulations, applying the appropriate calibration to the directors only.

7. The Document Console is absolutely essential for saving all documents, easy access and access to valid information for any required project.

8. Implement ISO quality management, accelerate the use of the system.

9. Regular meetings of staff to resolve problems faced by staff on the services provided by the Organization, and then to develop appropriate solutions to resolve them. 


\section{Capacity Building}

1. Continuous training to communicate the concept of total quality and scientific method applied.

2. The continuous motivation of employees to implement their total quality management.

3. Specialized conferences, professional readings and websites to provide more training for all employees and others to follow them to make sure their system is followed

4. Teamwork and participation, commitment to good management, customer focus and satisfaction, training and continuing education, organizational team behavior, management skills, management of resources and operations, in addition to providing advice.

5. Hire experts, provide more workshops and attend relevant courses.

6. Involve staff in making these decisions and suggestions to enhance the work environment in addition to continuous and renewed evaluation of the performance of the organization.

7. Identify and share all staff with systems and effectiveness.

8. Spreading awareness of the concept of TQM for all staff working in the organization as well as stakeholders and interest.

9. Sound management and more events, workshops and presentations to raise awareness among staff and put them in practice to understand the overall concept and best practices of TQM. Comprehensive implementation is also highly recommended.

\section{Summary and Analysis}

As noted by the responses and recommendations of the respondents about the best practices in the organization that most of the claims focus on teamwork, training, rehabilitation, the use of technology, the creation of committees and groups to communicate and meet to discuss challenges and decision-making. Workshops and awareness lectures for employees. The researcher believes that the organization depends on the creativity and exploitation of the resources available in the organization, exploiting opportunities to innovate solutions to provide the best services, as the management of the organization can agree with a consulting company specializing in TQM to draw and develop the best ways to use best practices. These claims will be included in the recommendations of this project.

\section{E.Q2 Please write your suggestion on how to support and improve the overall quality management in the organization, in terms of service development, staff performance and application of information technology.}

1. Follow up the monitoring of results and receive complaints and suggestions on time to review the objective and KPI of organizational efficiency of employees who review the work risk assessment.

2. Continue to hold training workshops for department directors and department heads on the concept of total quality standards.

3. Keep track of all documents and performance saved for each individual in the organization and provide them with more training and continuous evaluation programs.

4. Emphasis on the concepts of total quality and follow-up the implementation of staff within a general framework and deliberate steps.

5. Motivate ranks for employees, providing more training and time to meet their direct supervisor for feedback

6. The decision-maker must possess leadership qualities, involve all staff in decision-making, a rigorous decision-making approach, and a win-win solution for both the organization and suppliers.

7. Implementation of PDCA (Action-Verification-Action Plan)

8. After using the SWOT analysis, a buffer can be created by providing checklists to identify risks and opportunities for each project. The organization should implement TQM for each 
project. There must be a server to get data available for previous projects that highlight and mitigate risks.

9. The server should be used to retrieve data from previous projects and should include key points during project implementation.

10. To support and develop the work as a comprehensive system for the development of services in the field of work and promotion to the level of the employee essentially required lectures in the field of total quality.

11. Use technology and minimize the use of paper transactions.

12. Expand the scope of quality management in all departments of the ministry.

13. Create a suitable environment that suits the staff and organization.

14. Taking the views of others and increasing the awareness of employees in the sense of quality. Working with established and accepted policies in the organization. Increase the qualifying courses for all employees.

15. Upgrade the system, upgrade the computer being used. Provides easy access to each partition to maintain the best connection.

\section{Summary and Analysis}

Most of responses are focused on the interest of the employees in the DGPEA whether training, qualification and motivation. This requires the provision of techniques and programs to help employees get the job done. This also creates a suitable working environment and provide necessary supplies such as office equipment, materials and others. The need to conduct semiannual follow-up and analysis of the results to know the performance of staff and the efficiency and quality of the services provided. All the above points are very important for the management of the organization in enhancing the work and raising the efficiency of the performance of the staff in the organization. An employee is one of the most important resources that must be taken care of by management.

\section{Analysis and Findings of Interview}

\section{Interviewees' Summary}

The second research of this project is interview, it includes the five open questions related to search objectives. The researcher has done interviews with four directors who has heavy TQM experience in DGPEA. The interview answers to questions are summarized as follows:

\section{Q1. Do you see the application of TQM in DGPEA useful in improving work performance, quality and customer satisfaction? Give personal experiences?}

The goal of DGPEA TQM is to provide high quality services to achieve customer satisfaction as well as the vision and mission of the organization it seeks to achieve. To achieve this, a new department called the Organization's Quality Management Department was created to implement TQM and improve performance. This is to organize work and quality control services provided to customers. TQM is useful in improving the performance of employees at work. Whereas, all the work done by the organization has been enumerated and the steps and procedures have been reformulated to implement them in a way that is easier and faster than before. This is a significant variable in the service to be provided by the organization as the organization will become distinct in the quality of services provided to the beneficiaries.

Some of the personal experiences shared by the interviewees during the interview:

- When we started working in this organization, there was no specification or steps for any transaction, but there was a daily routine to work and learn to complete transactions from others, whether positive or negative. However, with TQM, all work has been surveyed and 
work specifications and drawings are drawn up, even for new employees. It will reduce effort and time as well as cost.

- The procedures and steps to complete the transactions between the sections were very large, and therefore there were loss of some documents and delay in completing the transactions in a timely manner. Some transactions are suspended and pending signature by officials for being on vacation or on a business assignment outside the country.

\section{Q2. What are the challenges and issues faced by staff in the performance process in the implementation of the TQM standards in the organization?}

The total quality standards are new to the staff. These, therefore needs time to be applied and implemented in the organization. Some employees do not want to change and just performed work as per the traditional method and this is one of the challenges faced by the organization in the application of TQM. The new change needs a few years, perhaps a year, for employees to work on TQM standards. There must be workshops and awareness on the importance of TQM to organization as well as the need for training and qualification to improve the performance of staff in the application of the system.

\section{Q3. What factors do you consider as the most important in improving the performance process in the application of TQM in the organization?}

To improve the performance process in the application of TQM in the organization, first the employee must be trained and should accept the changes to the new system. The workplace should be improved for change, for example, provide posters in each section explaining the work steps, the provision of electronic programs and services for employees, training and qualification of managers and heads of departments of the importance of total quality. One of the most important factors must also be to identify the challenges and problems faced by the employee during the first six months of application of the system. Transfer of expertise among employees and motivation and rewards are also necessary to raise employee morale and acceptance of change for improvement of the organization.

\section{Q4. Please cite briefly the role of information technology in the effective implementation of total quality management?}

Since work is highly technology related, the information technology is playing a great role in the success of the application of TQM in the Directorate. Technology facilitates and workflows facilitates communication among employees and to electronically transfers transactions. One of the new programs that facilitated the work is the existence of effective communication channels between organizations in the $\mathrm{MoH}$ is called (Al-Barwa) see Appendix (A9). It is also suggested that the services provided by this directorate be listed on a website where communication between the directorate and the authorities that will benefit from these services should be provided.

\section{Q5. In your opinion, what are the best quality practices of TQM in the organization?}

Best practices are methodologies or frameworks or work processes through which the organization's objectives are achieved. The success of quality in delivering outstanding services and adherence to best practices in the workplace, where the organization will become popular and reputation for success when using best practices should be given priority. In addition, the implementation of TQM in the Directorate will make this organization one of the best service providers in the $\mathrm{MoH}$ because of consistency in adopting the best practices. On the other hand, the use of best practices will require training, qualification and the use of best electronic applications as well as the commitment of employees and adherence to the application of standards of total quality in the workplace. This is a challenge for management as it requires management to meet this challenge by monitoring the work and the audit process every six months to ensure the use of best practices in the workplace. 


\section{Summary of the Chapter}

In this chapter, the presentation, analysis and results of quantitative and qualitative research (questionnaire and interviews) were discussed. The main findings of this research point to the importance of having TQM in all governmental and private organizations. This research used both deductive and descriptive statistical methods to obtain the final results. The results of the surveys were presented, discussed and analyzed by synthesis versus a review of the literature described in Chapter 2 of this paper. After presenting, analyzing and discussing the results, the next chapter will summarize the results and collect the results in general. The conclusions and recommendations will be discussed. Also, aspects related to future research will be put forward. In addition, the researcher's reflection on this huge research task will be presented as well.

\section{Conclusions and Recommendations}

\section{Introduction}

In this chapter, the discussions on whether this study has achieved all the objectives set for the study will be covered thoroughly as well as recommendations that will improve TQM performance and implementation in the DGPEA.

\section{Conclusions}

The previous TQM studies on healthcare has encouraged community work and cooperation in creating a healthy work environment. It was also revealed from those readings that TQM is a comprehensive method for improving quality in the organization. It focuses on the maintenance and continuous improvement of all operations as well as the functions of the organization and encourages cooperation between staff and enterprise management to improve process efficiency and quality of services and products while reducing operational costs. Furthermore, it was also concluded that TQM focuses on reducing redundancy and unnecessary functions. TQM has always focused on the main goal of customer satisfaction and that the enterprise must do its best to improve the customer experience. For better organization performance. Quality management is very crucial issue in an organization. Most studies had focused on the reasons why TQM strategies fail or are not generally implemented in most organizations. They do not look at the processes and the TQM framework.

\section{Conclusions}

\section{Research Objective}

\section{To Evaluate the Impact of TQM in DGPEA Overall Performance}

This objective focuses on the impact of the application of TQM on overall performance of the organization. The results indicated that TQM has a significant impact on performance. Most respondents praised the importance of TQM in improving the performance of the organization as well as the staff working in the organization, which will increase their efficiency, performance and behavior. It follows from the results of the analysis in Chapter 4 that TQM is important in improving performance and improving the image of the organization, both for stakeholders and customers. Respondents emphasize improved performance by applying quality standards, improving service quality and customer satisfaction to the services provided by the organization.

These results demonstrated the impact of TQM strongly on improving employee performance and service quality. TQM has a direct impact on employee performance and work optimization with minimal effort and cost, due to the existence of standards and compliance for each service. This is 


\section{Journal of Student Research}

Fourth Middle East College Student Research Conference, Muscat, Sultanate of Oman

due to support from FAO's senior management. These results emphasize the need to apply TQM in all services and branches of the $\mathrm{MoH}$ due to its positive impact on improving performance and increasing awareness in dealing with customers at DGPEA.

TQM standards and policies focused on establishing effective communication and administrative and technological channels between the directorates. This facilitates interdepartmental work and the completion of work in record time with improved performance. It helps the workflow of each employee and the amount of time and effort required for each activity or process.

\section{To Evaluate the Role of IT in TQM and it's Overall Impact in Improving DGPEA Performance}

This goal focused on exploring the role of IT in improving the work and staff performance of DGPEA. The results showed that the employee understood the role of information technology in facilitating and accelerating work, but a small percentage still needed awareness and training to use information technology in carrying out work.

There was a demand to include the services provided by the organization through information technology so that staff could develop their skills and perform their job duties using different hardware and software. The use of technology will improve the performance of the employee and develop his abilities and efficiency in the use of various applications in the completion of work. The results confirmed that technology applications are critical to increasing efficiency and effectiveness in DGPEA. Respondents agreed with this and need to use more applicable and accessible t technology and automated facilities. Some results showed that the use of IT applications lead to challenges and problems, including the issues of hacking and viruses. Employees should be informed about how to use the system with caution and not display information to others. Further training and guidance will solve this problem, and the use of reliable and well-known software is important for the organization to store data and avoid stealing information.

\section{To Assess the TQM Best Practices in DGPEA}

Best practices are the most important steps adopted by the institution in the management of total quality. In addition, this should provide channels of communication with customers to obtain satisfaction with the quality of services, as well as to clarify the best practices on which the organization depends on the use of standards of total quality. This objective will define the processes, policy and clear framework for quality performance.

As evidenced by the results of the analysis, some staff need more awareness to adopt TQM practices. In addition, there is a gap in some employees to accept and understand more comprehensive quality standards such as ISO 9001/2015. So here, staff needs to do more workshops about "ISO 9001/2015". This is to increase staff knowledge and ability to perform best practices in TQM as well as to learn about the organization's policy in implementing TQM. The results indicate that DGPEA senior management is very interested in implementing best practices. This is why all departments have adopted best management practices for TQM standards in DGPEA. With a very small percentage of employees who do not want to change, they will be gradually trained and monitored by the Quality Management Department. The bottom line of this goal is to do the right work from the first time and every time, means avoiding mistakes, as well as breaking the client's expectations, providing better service to the customer than expected. To make this work, management should help employees avoid making any mistake in the workplace.

Recommended TQM best practices are as follows. Top-management commitment, Teamwork, Operations management, Resource Management, Training and development. Organization behavior and culture, Focusing on follow-up, Monitoring and auditing, Evidence based decision making and Continuous improvement. 


\section{To Develop a Framework for Improving TQM Practices in DGPEA}

The results showed that TQM standards enable DGPEA managers and officials to strategically plan and optimize business development by implementing standard operating procedures so it can be referenced in any period of time. More so, there are standards and policies that defines the processes for each job and service performed by the organization because it helps in strategic planning and improvement of work and development. Therefore, procedures would be easy for any new employee to learn all the processes and work activities. There are a number of new employees who have been recruited in the last 2-3 years who need more care in understanding the framework and best practices for TQM.

Respondents in TQM viewed the need to define the organization's vision and mission because it is important to have strategic goals for the company. The results supported the development of future action plans, possibly over the next five years. TQM is useful in the organization to provide much needed guidance in improving the goals and objectives of the organization. It helps the organization focus more on improving its operations and production. This can improve the organization's image and overall expectations. This increases the number of customers receiving the best services that have become of high quality. The formation of committees is really an important task in the organization to achieve successful workflow. Most employees completed work as per TQM guidelines but results also showed that some lacks commitment to deliver a timely and efficient task. Therefore, management should prepare training courses for these staff as well as awareness programs on time management. There are several reasons for organization to use frameworks to help maintain a focus on the goals it has been planned to achieve.

The first important step is to tailor the right framework to achieve the organization's objective or perhaps a project that the organization would like to achieve. The essential part of choosing the right management is self-reflection in the organization. It focuses on the goal that the organization would like to achieve with the search for key strengths and weaknesses. All these factors will help the administration to choose the best strategic framework to achieve the goals.

The second step is to apply the chosen framework to the objectives of the organization. Management should think carefully about choosing each goal you create to fit the chosen framework. During the establishment of the organization's strategic objectives, the strategic framework is applied to the objectives. Thus, this process will force management to think deeply about the alignment of objectives, strategic framework and overall vision of the organization.

The third and final step is to review the organization's plan against the chosen framework. There are tools that will help analyze and show results on the compatibility of the strategic plan with the strategic framework such as the use of Cascade. This tool allows you to view the percentage of overall strategic objectives and each component shows the percentage of the framework elements. It will also help determine the amount of concentration for each element in the framework.

Figure 4. TQM Framework

\section{Recommendations}

This section will contain three sets of recommendations addressing senior management concerns, operational TQM issues and future research.

\section{Recommendations for TQM operational issues}

This recommendation will strengthen the strategies adopted in the application of TQM in the organization in accordance with international standards and guidelines by aligning its impact with the strategic mission and vision and goals of the organization. This requires the formation of a team 


\section{Journal of Student Research}

Fourth Middle East College Student Research Conference, Muscat, Sultanate of Oman

specialized in quality management to conduct a comprehensive inventory of the activities and transactions carried out by the organization internally and externally. There must be hiring of a specialist consultant in the field of quality management who would assist the team in formulating guidelines for new TQM policies. There must be qualifying process for members of the quality management team to come up with team who would be in unity and commitment in implementing better TQM policies for DGPEA. Members of the quality management team should supervise and follow up as well the implementation of quality standards, and use the steps adopted for that. The audit will be performed twice a year. Thus, the workflow will be checked according to the TQM plan of the organization. There should be listing of all services provided by the Directorate on the website of the Ministry of Health, with the full description of each service and its requirements in completing the task. This will greatly facilitate timely completion of task by DGPEA and customers or any organizations requesting the service. Genuine teamwork with quality team is also recommended because it contributes greatly to efficiency, increased production and the creation of a community within the organization. All these recommendations will contribute to improving the image of the organization and improving the efficiency of the TQM system. There must be full compliance to customer requirements to improve service quality and gain their customer satisfaction. In addition, the continued support by senior management is the success of implementation of the TQM standards in the organization.

\section{Recommendations for Senior Management in the Organization}

Improving the image of the organization in the market comes from the satisfaction of customers who receive the service from the organization, therefore senior management must be keen to provide the best services to customers and gain their satisfaction. Quality is one of the priorities of successful management, and the vision and mission of the organization suggest to provide the best services to the community and customers.

The Department's commitment to continuous support in the implementation of TQM in the organization will help to convince staff of this decision. They must work accordingly to implement it according to the directions/vision of the organization. It also requires management to contract with an international consultancy office to oversee and follow up on the successful implementation of TQM and then obtain the international certification in the field of quality.

\section{Recommendations for Future Research}

This research focused on the reformulation of activities and steps to implement the transaction with an international consultant in the field of total quality. All services are also included in the website to be available to the beneficiaries. One of the final objectives of this research was to eliminate the use of paperwork in unnecessary transactions and to use information technology to communicate and end transactions.

The first recommendation for future research is to conduct more qualitative studies on the international standards of total quality approved by international organizations (ISO). It is then compared with governmental as well as private institutions and bodies in applying these standards. This aims to develop and increase the number of institutions that implement TQM in their business and products.

The second recommendation for future research is to conduct a research study on the quality of staff performance and constraints and challenges faced in the implementation of work, where there are many obstacles and challenges facing the employee, including the use of modern technologies in the performance of work as well as the application of quality standards.

The third recommendation is to measure the role of technology in the success of the application of quality management (ISO 90001/2015). Some variables can be added to the research such as the 


\section{Journal of Student Research}

Fourth Middle East College Student Research Conference, Muscat, Sultanate of Oman

size of the organization, the techniques used and the cost. The research will expand to conduct more questionnaires and statistical analysis to get the best results. This research can give better future results in the field of TQM.

\section{Summary}

The application of TQM in organizations revolutionized the business world and contributed to improved performance and quality of products and services. The reputation and image of the organizations applying the TQM has become unique in the quality of its services. The orientation of quality management in the use of modern technology is one of the most important decisions to develop and improve the performance and use of available resources optimization. DGPEA is one of the successful directorates in providing and providing services and establishing hospitals and health centers in the Sultanate of Oman. This success comes to teamwork and the use of effective communication channels between organizations in the Ministry of Health. This has contributed to satisfaction in the work environment and building relationships between employees from the bottom up the career pyramid. Hence, there must be a high level of attention to sustainability in TQM as well as the application of international standards for quality management to provide the highest quality services to the beneficiaries. The life cycle of the employee in the organization and its role in achieving and successfully improving the image of the organization must also be taken into account. The role of technology is effective in the speed of implementation and completion of transactions and the disposal of paper use management must gradually phase out the use of paper and increase the use of technology.

\section{References}

Adeoti, J. O. (2011). Total quality management (TQM) factors: An empirical study of Kwara state government hospitals. Studies on Ethno-Medicine, 5(1), 17-23.

Adindu, A. (2010). Assessing and assuring quality of health care in Africa. African Journal of Medical Sciences, 3(1), 31-36.

Agus, A. (2011). Enhancing production performance and customer performance through total quality management (TQM): strategies for competitive advantage. Procedia-Social and Behavioral Sciences, 24, 1650-1662.

Altbach, P. G., Reisberg, L., \& Rumbley, L. E. (2009). Trends in global higher education: Tracking an academic revolution.

Anoye, B. A. (2015). Implementation Of ISO 9000 Quality Management System Within The Manufacturing And Service Industry Of Ivory Coast Borget Alfred Anoye. Retrieved from https://pdfs.semanticscholar.org/8544/62a117b228956d5751ca68c78f5dea36b434.pdf

Arasli, H. (2002). Diagnosing whether northern Cyprus hotels are ready for TQM: an empirical analysis. Total Quality Management, 13(3), 347-364.

Arditi.D \& Hurat.H, 2000. Total Quality Management in Construction Process. International Journal of Project Management, Volume 15, p. 4.

ASQ, 2019. ASQ. [Online] Available at: https://asq.org/quality-resources/quality-glossary/t [Accessed 215 2019].

Balasubramanian, M. (2016). Total quality management [TQM] in the healthcare industry-challenges, barriers and implementation developing a framework for TQM implementation in a healthcare setup. Science Journal of Public Health, 4(4), 271-278. 


\section{Journal of Student Research}

Fourth Middle East College Student Research Conference, Muscat, Sultanate of Oman

Benavides-Velasco, C. A., Quintana-García, C., \& Marchante-Lara, M. (2014). Total quality management, corporate social responsibility and performance in the hotel industry. International Journal of Hospitality Management, 41, 77-87.

Bernardo, M., Simon, A., Tarí, J. J., \& Molina-Azorín, J. F. (2015). Benefits of management systems integration: a literature review. Journal of Cleaner Production, 94, 260-267.

Boone, L. E., \& Kurtz, D. L. (2012). Contemporary Marketing, 2013 Update. Cengage Learning.

Bou-Llusar, J. C., Escrig-Tena, A. B., Roca-Puig, V., \& Beltrán-Martín, I. (2009). An empirical assessment of the EFQM Excellence Model: Evaluation as a TQM framework relative to the MBNQA Model. Journal of Operations Management, 27(1), 1-22.

Calabrese, A., \& Corbò, M. (2015). Design and blueprinting for total quality management implementation in service organisations. Total Quality Management \& Business Excellence, 26(7-8), 719-732.

Charantimath, P. M. (2011). Total Quality Management. Pearson Education India.

Claver-Cortés, E., Pereira-Moliner, J., José Tarí, J., \& Molina-Azorín, J. F. (2008). TQM, managerial factors and performance in the Spanish hotel industry. Industrial Management \& Data Systems, 108(2), 228-244.

Contributor, 2019. sciencing. [Online] Available at: https://sciencing.com/interpret-likertsurveys-8573143.html[Accessed 18 2019].

Dahlsrud, A. (2008). How corporate social responsibility is defined: an analysis of 37 definitions. Corporate Social

Responsibility and Environmental Management, 15(1), 1-13.

Dale, B. (2011). Total Quality Management, (Revised Edition). Pearson Education India.

D. \& H., 2000. Total Quality Management in Construction Process. International Journal of Project Management, Volume 15, p. 4.

Doyle, P. (2009). Value-based Marketing: Marketing Strategies for Corporate Growth and Shareholder Value. John Wiley \& Sons.

Elbishti, E. K. A. M. (2015). The Degree of JIT in Mineral Oil and Asphalt Industries in Libya.

Escobar, S., 2015. Total Quality Management and Six SIGMA. s.l.:Clanrye International.

Fonseca, L. M. (2015). From Quality Gurus and TQM to ISO 9001: 2015: a review of several quality paths. International Journal for Quality Research (IJQR), 9(1), 167-180.

Friedli, T., Basu, P., Bellm, D., \& Werani, J. (2013). Leading Pharmaceutical Operational Excellence: Outstanding Practices and Cases. Springer Science \& Business Media.

GoodTherapy, 2019. Workplace Issues. [Online] Available at: https://www.goodtherapy.org/learnabout-therapy/issues/workplace-issues [Accessed 18 2019].

Graham, M., \& Woo, J. (2009). Fuelling Economic Growth: The Role of Public-private Sector Research in Development. IDRC. 


\section{Journal of Student Research}

Fourth Middle East College Student Research Conference, Muscat, Sultanate of Oman

GUN, 2019. GUN Operating System. [Online] Available at:https://www.gnu.org/software/pspp/ [Accessed 217 2019].

Green, T. J. (2012). TQM and organisational culture: how do they link? Total Quality Management \& Business Excellence, 23(2), 141-157.

ISO. (2019). ISO 9000 family - Quality management. Retrieved June 26, 2019, from https://www.iso.org/iso-9001-quality-management.html

Jaafari, A., 2001. Management of Risk, uncertainties and opportunities on project: time for a fundamental shift.. International Journal of Project management, pp. 1(2), 89-101.

James, B. C., \& Savitz, L. A. (2011). How Intermountain trimmed health care costs through robust quality improvement efforts. Health Affairs, 30(6), 1185-1191.

Joseph, T. (2013). Healthcare Information Technology Innovation and Sustainability: Frontiers ... Google Books. Retrieved June 26, 2019, from https://books.google.co.ke/books

Kaplan, R. S. (2005). The Balanced Scorecard: Measures that Drive Performance. Harvard Business Review.

Kaynak, E., \& Rogers, R. E. (2013). Implementation of Total Quality Management: A Comprehensive Training Program. Routledge.

Kelkar S. A. (2010). Hospital Information Systems : A Concise Study. PHI Learning Pvt. Ltd.

Kyriazoglou, J. (2012). Business Management Controls: A guide. IT Governance Ltd.

Lam, S.-Y., Lee, V.-H., Ooi, K.-B., \& Lin, B. (2011). The relationship between TQM, learning orientation and market performance in service organisations: An empirical analysis. Total Quality Management \& Business Excellence, 22(12), 1277-1297.

Leon, A. (2008). ERP Demystified. Tata McGraw-Hill Education.

McConnell, C. R. (2014). The Effective Health Care Supervisor. Jones \& Bartlett Publishers.

Mehralian, G., Nazari, J. A., Zarei, L., \& Rasekh, H. R. (2016). The effects of corporate social responsibility on organizational performance in the Iranian pharmaceutical industry: The mediating role of TQM. Journal of Cleaner Production, 135, 689-698.

Mendenhall, M. E., Osland, J., Bird, A., Bird, P. of I. A. and H. of the G. S. and L. A. in the C. of B. A., Oddou, G. R., \& Maznevski, M. L. (2013). Global Leadership: Research, Practice and Development. Routledge.

Mohammad Mosadeghrad, A. (2014). Why TQM programmes fail? A pathology approach. The TQM Journal, 26(2), 160-187. https://doi.org/10.1108/TQM-12-2010-0041

Mosadeghrad, A. M. (2014). Essentials of total quality management: a meta-analysis. International Journal of Health Care Quality Assurance, 27(6), 544-558.

Nallusamy, S. (2016). A proposed model for sustaining quality assurance using TQM practices in small and medium scale industries. 22, 184-190. Trans Tech Publ.

Needham, D., \& Dransfield, R. (2001). Business Studies for You. Nelson Thornes. 


\section{Journal of Student Research}

Fourth Middle East College Student Research Conference, Muscat, Sultanate of Oman

Noe, R. A., Hollenbeck, J. R., Gerhart, B., \& Wright, P. M. (2017). Human resource management: Gaining a competitive advantage. McGraw-Hill Education New York, NY.

Oakland, J. S. (2012). TQM: Text with Cases. Routledge.

Palmer, I., Akin, G., \& Dunford, R. (2009). Managing Organizational Change: A Multiple Perspectives Approach. McGraw-Hill Higher Education.

Rawlins, R. A. (2008). Total Quality Management (Tqm). AuthorHouse.

Salaheldin, S. I., Fathi, S., \& Shawaheen, M. S. (2015). Critical Success Factors For Total Quality Management Implementation in Jordanian Healthcare Sector. European Scientific Journal, ESJ, 11(13).

Sanchez-Serrano, I. (2011). The World's Health Care Crisis: From the Laboratory Bench to the Patient's Bedside. Elsevier.

Su, C.-H., Tsai, A., \& Hsu, C.-L. (2010). The TQM extension: Total customer relationship management. Total Quality Management, 21(1), 79-92.

Talib, F., \& Rahman, Z. (2010). Studying the impact of total quality management in service industries. Talib, F. and Rahman, (2010), 249-268.

Talib, F., Rahman, Z., \& Azam, M. (2011). Best practices of total quality management implementation in health care settings. Health Marketing Quarterly, 28(3), 232-252.

Tang, Z., Chen, X., \& Wu, Z. (2010). Using behavior theory to investigate individual-level determinants of employee involvement in TQM. Total Quality Management, 21(12), 1231-1260.

Tarí, J. J. (2011). Research into quality management and social responsibility. Journal of Business Ethics, 102(4), 623-638.

Teh, P.-L., Yong, C.-C., Arumugam, V., \& Ooi, K.-B. (2009). Does total quality management reduce employees' role conflict? Industrial Management \& Data Systems, 109(8), 1118-1136.

Tidd, J., \& Bessant, J. R. (2018). Managing innovation: integrating technological, market and organizational change. John Wiley \& Sons.

Tung, A., Baird, K., \& Schoch, H. (2014). The relationship between organisational factors and the effectiveness of environmental management. Journal of Environmental Management, 144, 186-196.

Weidinger, C., Fischler, F., \& Schmidpeter, R. (2013). Sustainable Entrepreneurship: Business Success through Sustainability. Springer Science \& Business Media.

Yih, Y. (2016). Handbook of Healthcare Delivery Systems. CRC Press. 